Atos de Pesquisa em Educação - ISSN 1809-0354

Blumenau, v.14, n.2, p.478-500, mai./ago. 2019

DOI: http://dx.doi.org/10.7867/1809-0354.2019v14n2p478-500

\title{
PERCEPÇÃO AMBIENTAL DOS ALUNOS DE UMA ESCOLA PÚBLICA ESTADUAL ACERCA DO RIO SARAPUÍ, MUNICÍPIO DE DUQUE DE CAXIAS, RIO DE JANEIRO
}

\section{PERCEPCIÓN AMBIENTAL DE ESTUDIANTES DE UNA ESCUELA PÚBLICA ESTATAL ACERCA DE RÍO SARAPUÍ, MUNICIPIO DE DUQUE DE CAXIAS, RÍO DE JANEIRO}

\section{ENVIRONMENTAL PERCEPTION OF STUDENTS FROM A PUBLIC STATE SCHOOL ON THE SARAPUÍ RIVER, MUNICIPALITY OF DUQUE DE CAXIAS, RIO DE JANEIRO}

\author{
NASCIMENTO, Juliana Macedo Lacerda \\ julym.bio@hotmail.com \\ UERJ - Universidade do Estado do Rio de Janeiro e FIOCRUZ \\ https://orcid.org/0000-0002-8568-6122 \\ BRANDÃO, Lucas de Esquivel Dias \\ lucasdesquivel@hotmail.com \\ PUC Minas - Pontifícia Universidade Católica de Minas Gerais \\ https://orcid.org/0000-0003-2777-9440 \\ BARROS, Marcelo Diniz Monteiro de \\ marcelodiniz@pucminas.br \\ PUC Minas - Pontifícia Universidade Católica de Minas Gerais e FIOCRUZ. \\ https://orcid.org/0000-0003-4420-5406
}

RESUMO Em 2012 foi feita uma investigação com três turmas de $7^{\circ}$ Ano do Ensino Fundamental em uma escola pública Estadual no Rio de Janeiro, localizada no município de Duque de Caxias. Através de um questionário semiestruturado, almejou-se identificar conhecimentos prévios dos estudantes sobre o rio Sarapuí em interfaces com assuntos relacionados à saúde e às aulas de ciências. Mesmo diante da proximidade geográfica entre o rio, a escola e a vida dos estudantes, os resultados mostraram um grande abismo entre ideias prévias e conhecimentos científicos sobre ambiente e saúde, apontando dessa forma a necessidade de maiores intervenções nesse campo. Espera-se que esta pesquisa subsidie a elaboração de campanhas educativas e projetos de intervenção ambiental, principalmente nas 21 favelas que estão presentes ao longo do percurso do rio Sarapuí.

Palavras-chave: Educação Ambiental. Educação Básica. Rio Sarapuí.

RESUMEN En 2012 se realizó una investigación con tres clases de $7^{\circ}$ anõ de educación fundamental en una escuela pública estatal en Río de Janeiro, ubicada en el municipio de Duque de Caxias. A través de un cuestionario semiestructurado, el objetivo era identificar los conocimientos previos de los estudiantes sobre el río Sarapuí en interfaces con asignaturas relacionadas con la salud y clases de ciencias. Incluso teniendo en cuenta la proximidad geográfica entre el río, la escuela 
y la vida de los estudiantes, los resultados mostraron un gran abismo entre las ideas previas y el conocimiento científico sobre el medio ambiente y la salud, lo que señala la necesidad de nuevas intervenciones en este campo. Se espera que esta investigación subsidie la elaboración de campañas educativas y proyectos de intervención ambiental, especialmente en los 21 barrios marginales que están presentes a lo largo del río Sarapuí.

Palabras clave: Educación ambiental. Educación básica. Río Sarapui.

ABSTRACT In 2012 an investigation was carried out with three classes of the 7th Year of Elementary School in a state public school in Rio de Janeiro, located in the municipality of Duque de Caxias. Through a semi-structured questionnaire, it was sought to identify students' previous knowledge about the Sarapuí River in interfaces with subjects related to health and science classes. Even in the face of the geographic proximity of the river to the school and the students' lives, the results showed a great gap between previous ideas and scientific knowledge about environment and health, pointing out the need for greater interventions in this area. This research is expected to subsidize the elaboration of educational campaigns and environmental intervention projects, mainly in the 21 shantytowns that are present along the course of the Sarapuí river.

Key words: Environmental Education. Basic Education. Sarapuí River.

\section{INTRODUÇÃO}

Enfatizado em diversos meios de comunicação, o termo Educação Ambiental foi cunhado em 1965 no Reino Unido e fortalecido ao longo dos últimos anos por diferentes culturas e interesses entre as nações (COSTA; FARIAS, 2008). No Brasil, antes mesmo dessa denominação formal, são encontrados relatos da década de 1950 mostrando preocupação e contribuições de professores do Ensino Fundamental e Superior no que tange ao ensino do tema (KRASILCHIK; CARVALHO; SILVA, 2010). Instituído em 1996 como Tema Transversal dos Parâmetros Curriculares Nacionais (PCNs), o ensino do meio ambiente teve sua dimensão biológica ou científica ampliada para questões atreladas à todas as disciplinas escolares. Essa inserção ou reconhecimento deu-se devido ao fato do tema perpassar fatos sociais, econômicos, históricos e culturais (BRASIL, 1998; BACCEGA, 2000). Diante desse desafio, os PCNs ressaltam que o ensino do meio ambiente deve ter a finalidade de ajudar os alunos na construção de uma visão mais ampla, voltada à relação do uso e cuidado do ambiente com a qualidade de vida em todas as suas esferas (BRASIL, 1998). Em 1999, a Política Nacional de Educação 
Ambiental (PNEA), instituída pelo Governo Federal, enfatizou ser responsabilidade da escola trabalhar o tema Educação Ambiental (EA) em todas as esferas de ensino, dispondo para os anos finais do Ensino Fundamental a incumbência de "desenvolver o raciocínio crítico, prospectivo e interpretativo das questões socioambientais bem como a cidadania ambiental" (MELLO; TRAJBER, 2007, p.30).

Pesquisas voltadas à Educação Ambiental (EA) Crítica defendem, entre outras abordagens, reflexões interdisciplinares, conhecimentos históricos e sociais, além dos biológicos e geográficos tradicionalmente abordados em EA a fim de obter resultados mais efetivos nesse campo (BOMFIM, 2008; GUIMARÃES, 2000; 2007; LOUREIRO, 2004; LAYRARGUES, 1997).

Para Guimarães:

Em uma concepção crítica de Educação Ambiental, acredita-se que a transformação da sociedade é causa e consequência da transformação de cada indivíduo, há uma reciprocidade dos processos no qual propicia a transformação de ambos. Nesta visão o educando e o educador são agentes sociais que atuam no processo de transformações sociais; portanto, o ensino é teoria/prática, é práxis. Ensino que se abre para a comunidade com seus problemas sociais e ambientais, sendo estes conteúdos de trabalho pedagógico. Aqui a compreensão e atuação sobre as relações de poder que permeiam a sociedade são priorizados, significando uma educação política (GUIMARÃES, 2000, p.17).

Numa perspectiva histórica, no que diz respeito aos recursos hídricos do Estado do Rio de Janeiro, mais precisamente aos rios que atravessam a cidade, os relatos históricos confirmam a ocupação de suas margens primitivamente por índios Tupinambás e Tamoios, cujos cuidados eram plenamente sustentáveis (ARAÚJO; COREIXAS, 2002). Numa trajetória de aproximadamente 500 anos, os rios cariocas tiveram seus recursos naturais explorados e foram usados como via de escoamento de produtos agrícolas e minerais até a Baía de Guanabara, hoje, porém, representam um cenário de destruição que compromete a saúde pública e que "respinga" na educação local um senso de responsabilidade, preservação e sensibilização (ARAÚJO; COREIXAS, 2002).

Objetivando identificar os conhecimentos prévios de discentes de uma escola pública Estadual sobre o rio Sarapuí, cujas margens ficam a 500 metros da escola, é necessária uma breve descrição histórica e geográfica do rio.

O rio Sarapuí tem sua nascente situada na Serra de Bangu, no maciço da Pedra Branca, do município do Rio de Janeiro. Fica a uma altitude de 900 metros e 
foi incorporado à bacia do Iguaçu no início do século XX (ALMEIDA et al., 2013; CORDEIRO, 2006; CAMPOS, 2004). A partir da nascente, o mesmo segue um percurso no sentido sudoeste por cerca de 30 a $36 \mathrm{Km}$ até a sua foz, no rio Iguaçu. Em seguida, juntamente com o rio Iguaçu, segue o sentido Oeste Leste até a Baía de Guanabara. Com uma área de drenagem de aproximadamente $726 \mathrm{Km}^{2}$, dos quais $168 \mathrm{Km}^{2}$ representam a sub-bacia do rio Sarapuí (BARBOSA et al., 2012; CARNEIRO; MIGUEZ, 2012; SILVEIRA et al., 2011; CARNEIRO et al., 2010), o rio Sarapuí atravessa os seguintes municípios do Rio de Janeiro: Belford Roxo, Mesquita, Nilópolis, Nova Iguaçu, São João de Meriti e Duque de Caxias (ARAÚJO; COREIXAS, 2002).

Esse rio passou a fazer parte da bacia do rio Iguaçu no início do século $X X$, devido às obras de saneamento na Baixada Fluminense, durante o governo de Getúlio Vargas, quando seus cursos médio e inferior foram retificados, tendo sua foz desviada para o curso inferior do rio Iguaçu. Anteriormente o rio desaguava diretamente na Baía de Guanabara. Era um rio autônomo, mas hoje deságua no rio Iguaçu, na cidade de Duque de Caxias, na região da Baixada Fluminense (SANTANA, 2011).

Como descreve Santana (2011):

No século XVII, o rio Sarapuí transportava riquezas, passavam a produção agrícola dos engenhos de cana de açúcar, nos antigos distritos de Maxambomba (Nova Iguaçu), Meriti, e Nossa Senhora do Pilar (Duque de Caxias) para o porto do Rio de Janeiro. Mais tarde, no século XVIII, foi usado como escoadouro para a Europa, com escala no Rio de Janeiro, do ouro que vinha das Minas Gerais (SANTANA, 2011, p.2).

Atualmente, o rio Sarapuí percorre quase toda a totalidade de seu curso em áreas com elevada densidade populacional. Ao longo de seu percurso existem cerca de 21 favelas, as quais são pouco providas de saneamento básico, o que faz com que o lixo e os esgotos domésticos sejam lançados diretamente no seu corpo d'água (BARBOSA et al., 2012; CREA, 2013; CAMPOS, 2004). Além disso, também ocorre no mesmo, o despejo de esgotos industriais não tratados, fazendo com que suas águas apresentem os nutrientes fósforo e nitrogênio como principais agentes tóxicos, tendo também uma toxicidade aditiva de metais, amônia e sulfeto. Tudo isso 
faz com que a qualidade das águas desse rio seja incompatível com a manutenção da vida aquática (PIRES, 2006).

\begin{abstract}
Com o passar dos anos o rio Sarapuí foi rodeado por inúmeras ocupações irregulares, hoje o número de favelas é presente em toda a sua extensão, atravessando as barreiras dos municípios. Em suma é uma população carente que buscou refúgio as margens do rio Sarapuí e vivem em condições desumanas, sem água encanada, luz, saneamento básico, com lixo por toda parte, animais transmissores de doenças, sem contar as enchentes que assolam a região nos períodos de pluviosidade alta. A população ribeirinha apenas é lembrada em períodos de eleição e durante todo o tempo sofre de doenças acarretadas pela poluição do rio (SANTANA, 2011, p.2).
\end{abstract}

O rio Sarapuí manifesta uma dinâmica caracterizada pela grande quantidade de transferência dos materiais gerados em sua bacia. Isso faz com que a região próxima à sua foz, apresente uma área sedimentar caracterizada por grandes quantidades de matéria orgânica, o que aumenta, portanto, o potencial de retenção e estocagem de contaminantes na área (CORDEIRO, 2006).

O estudo de Silveira et al. (2011) mostra que o rio Sarapuí, quando comparado com o Iguaçu, apresenta uma maior concentração de metais e Demanda Bioquímica de Oxigênio (DBO), que conhecidamente é um indicativo de ambiente eutrofizado. Comparando os três pontos de coleta de água realizados no rio Iguaçu com o único ponto de coleta feito na foz do rio Sarapuí, percebeu-se que as concentrações dos metais Arsênio (As), Cromo (Cr), Cobre (Cu), Chumbo (Pb), Vanádio (V), Zinco (Zn), e a DBO apresentaram valores maiores para o rio Sarapuí do que os valores de concentração desses mesmos materiais e DBO analisados nos três pontos de coleta do rio Iguaçu. Isso evidencia mais uma vez o quão poluído esse curso de água do rio Sarapuí se encontra na atualidade.

Barrocas e Wasserman (1995), em um trabalho de revisão, registraram a existência do mercúrio no rio Sarapuí, metal pesado que do ponto de vista toxicológico é um dos mais nocivos, tanto em amostras de sedimentos retiradas do rio, quanto em amostragens de água do mesmo. Almeida et al. (2013) registraram uma concentração da DBO 12,4 vezes maior do que a permitida pela resolução CONAMA 357/05 (BRASIL, 2005), mostrando desse modo, que existe uma grande quantidade de matéria orgânica na água e uma baixa quantidade de oxigênio disponível na mesma. Foi observado também, a ocorrência de Cobre (Cu) e Cádmio 
(Cd), além de um nível de Chumbo $(\mathrm{Pb})$ 10,3 vezes maior do que o permitido pela resolução CONAMA 357/05.

Esse conjunto de fatores apresentados anteriormente ajuda a agravar as condições de vida da população ribeirinha residente ao longo do rio Sarapuí, que de alguma forma utiliza ou entra em contato com a água desse rio. Isso faz com que essa população sempre fique sujeita a riscos de doenças de veiculação hídrica, além de outras enfermidades causadas pela contaminação da água pelos diferentes metais.

Portanto, a percepção ambiental dessa população sobre o rio Sarapuí é de extrema importância, já que possibilita o entendimento de como os indivíduos compreendem esse ambiente, quais são suas fontes de satisfação e insatisfação em relação ao mesmo, tornando-se, dessa maneira, um instrumento relevante para a educação ambiental (EA) e para o uso dos órgãos responsáveis pela elaboração das políticas ambientais na tomada de decisões (OLIVEIRA; CORONA, 2008). O estudo dessa percepção permite o reconhecimento de cada um dos grupos locais envolvidos, facilitando assim, a realização de um trabalho de EA com bases locais (FRANCO et al., 2012; MALAFAIA; RODRIGUES, 2009; BEZERRA et al., 2008; MARIN, 2003; DEL RIO; OLIVEIRA, 1999).

Fernandes et al. (2004, p.33) definem percepção ambiental como sendo "uma tomada de consciência do ambiente pelo homem, ou seja, o ato de perceber o ambiente que se está inserido, aprendendo a proteger e a cuidar do mesmo". E mostram ainda que estudos nesse viés são significativos já que permitem a melhor compreensão das inter-relações existentes entre o homem e a natureza.

Assim sendo, entender as diferentes percepções, valores sociais, culturais, e as atitudes ambientais da comunidade local sobre esse espaço natural que se encontra transformado é fundamental (MELAZO, 2005; FERNANDES et al., 2004).

\section{METODOLOGIA}

A pesquisa foi do tipo descritiva, quantitativa/qualitativa, de campo e utilizou questionários (apêndice I) como instrumentos de coleta de dados (BARROS; LEHFELD, 2007). O que motiva o presente estudo a possuir viés quantitativo é: a) o 
objeto de estudo ser formado por fatos vistos e descritos, b) o tipo de instrumento de pesquisa ser um questionário com questões abertas e fechadas, c) e a apresentação dos resultados ocorrer em forma de gráficos (TURATO, 2005). Para o viés qualitativo: a) a amostragem ocorreu de forma intencionada, em que se buscou propositalmente indivíduos que vivenciam o problema em foco e/ou têm conhecimentos sobre ele, b) o perfil da amostra ser composto de poucos sujeitos, que representam características de uma subpopulação, c) e no tamanho da amostra o número de sujeitos ser definido em campo (TURATO, 2005). Nessa investigação, - Termo de Consentimento Livre e Esclarecido (TCLE) foi entregue aos responsáveis após a explicação da pesquisa. Somente com a assinatura dos responsáveis houve a validação das respostas dos questionários. A Resolução do Conselho Nacional de Saúde/Comissão Nacional de Ética em Pesquisa, de 2016, reconhece a importância dos Termos de Consentimentos Livres e Esclarecidos (TCLEs) e dos Comitês de Ética, mas registra a não necessidade da elaboração de TCLEs e das submissões aos Comitês de Ética, para questionários como o elaborado no presente estudo, no viés das Ciências Humanas e Sociais.

Em 2012 foi feita uma investigação com três turmas de $7^{\circ}$ Ano do Ensino Fundamental de uma escola pública Estadual no Rio de Janeiro, localizada no município de Duque de Caxias. A escolha da série ocorreu devido a afinidade do tema com os conteúdos do currículo mínimo (seres vivos/ saúde) e pelo fato de os alunos já terem tido contato, no ano anterior, com os conteúdos sobre o ambiente. Através de um questionário semiestruturado, almejou-se identificar que conhecimentos esses alunos tinham sobre o rio Sarapuí. Além dos conhecimentos geográficos, buscou-se saber se os alunos estabeleciam alguma relação, e qual era essa relação, entre a presença do rio, as aulas de ciências e a saúde da população ribeirinha.

\section{RESULTADOS/DISCUSSÃO}

Num total de 52 alunos matriculados nas três turmas, 46 tiveram seus TCLE assinados e, portanto, validadas as respostas. A faixa etária variou entre 11 a 15 anos, sendo 32 alunos do sexo feminino e 14 do sexo masculino. A escola cujas 
turmas foram pesquisadas fica às margens do rio Sarapuí, hoje totalmente poluído e contaminado.

Nos resultados encontrados, observa-se que a maior parte dos alunos compreende que o rio está comprometido pelas ações humanas que podem causar malefícios aos moradores (Figura 1). Essa é uma visão importante, já que atualmente a sociedade demonstra ter uma percepção sobre os problemas ambientais, embora a maioria das pessoas não conheça suas origens, consequências e formas de enfrentamento. $E$, por isso, podem acabar reproduzindo ideias distorcidas sobre determinado assunto (FERNANDES et al., 2004).

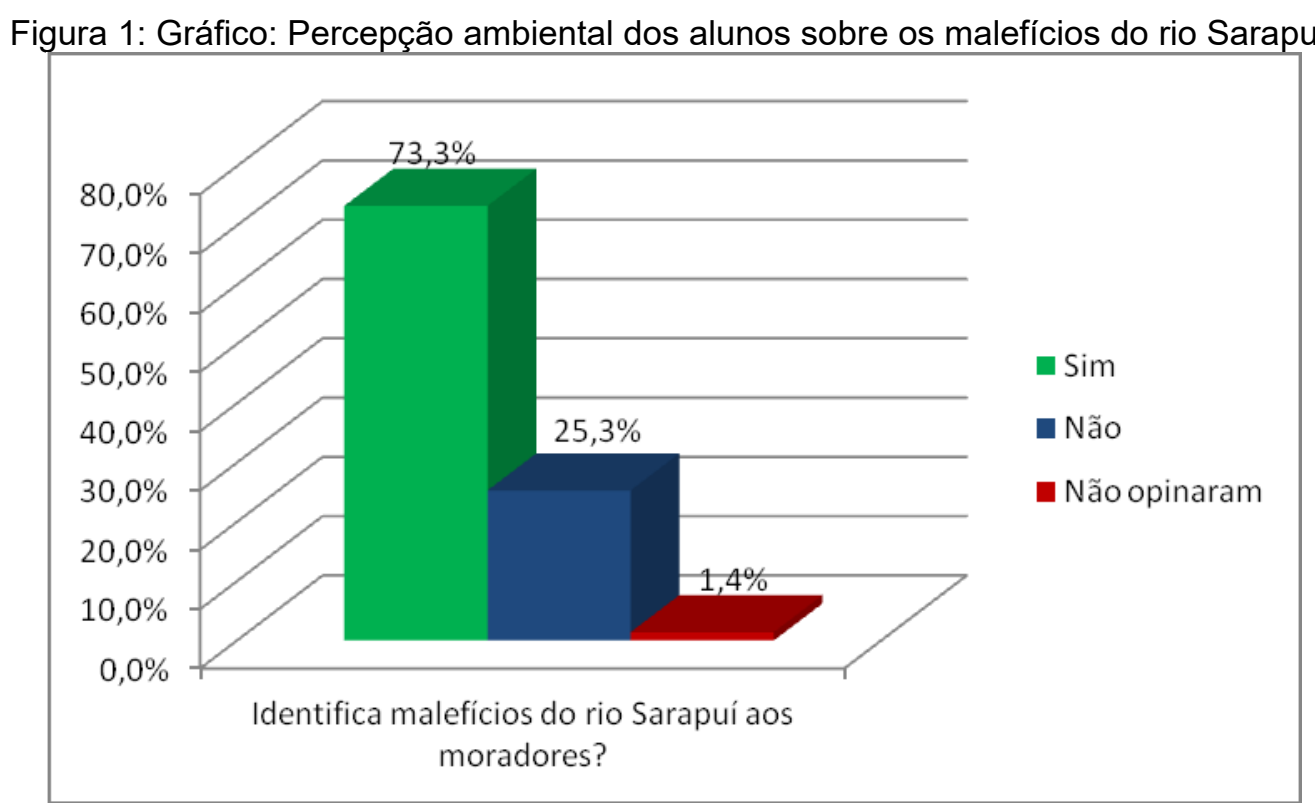

Fonte: Elaboração dos próprios autores.

Pesquisas em EA têm mostrado que é fundamental que os alunos conheçam o todo para compreender as partes (LISBOA; KINDEL; KROB, 2012). Na Figura 2, fica claro que o desconhecimento dos alunos pesquisados sobre a localização da nascente do rio Sarapuí é enorme. Esse fato abre perspectivas para o desenvolvimento de novos trabalhos de EA, sendo interessante, por exemplo, propor uma visita técnica a Serra de Bangu com esses estudantes; explicar como uma nascente surge; mostrar a importância de se evitar a construção de currais, chiqueiros, galinheiros, fossas sépticas, e impedir o acúmulo de lixo nas proximidades acima das nascentes (PENSAMENTO VERDE, 2014), dentre outros aspectos possíveis. 
Figura 2: Gráfico: Percepção ambiental dos alunos sobre a localização da nascente do rio Sarapuí.

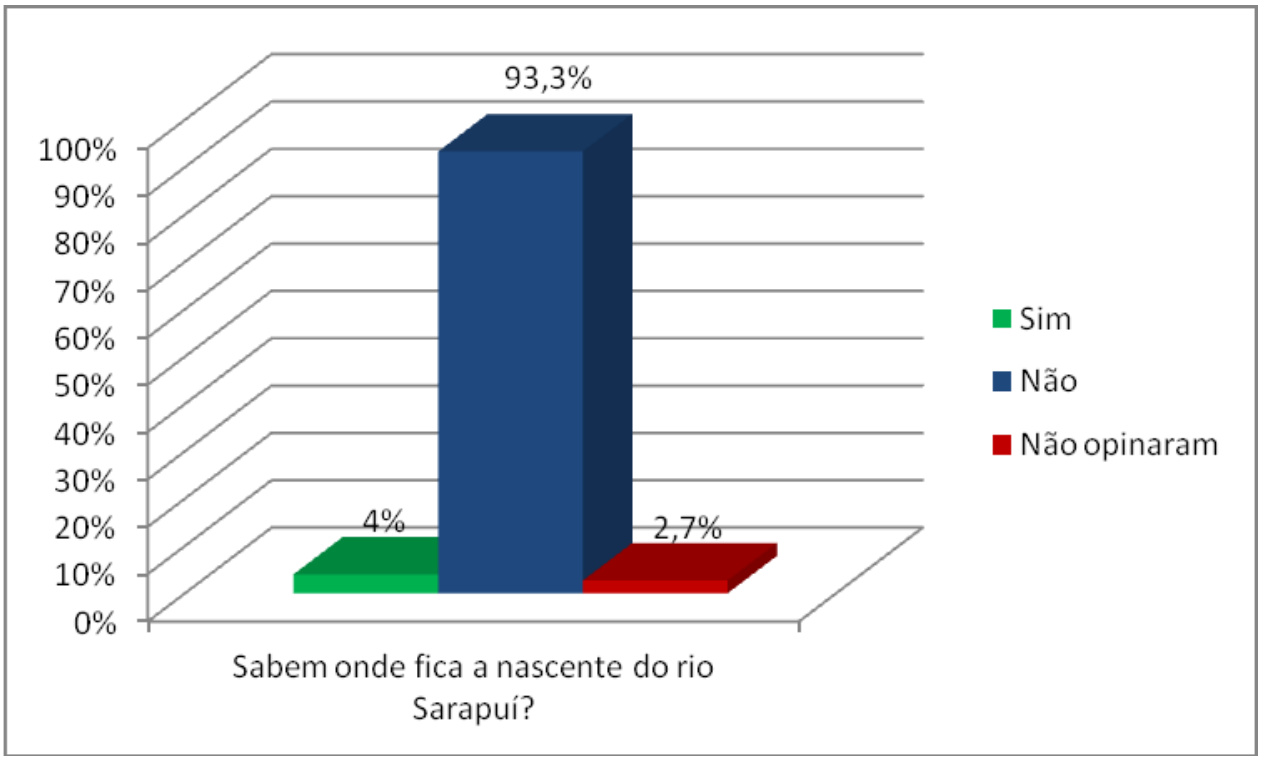

Fonte: Elaboração dos próprios autores.

A maior parte dos alunos entende que o rio está muito sujo e contaminado (Figura 3), o que é um dado relevante, pois de fato diariamente o rio recebe esgoto e lixo in natura (JUNQUEIRA, 2010a). O estudo de Moura e Pereira (2016) registra que não é raro ocorrer inundações no rio Sarapuí, visto que o mesmo apresenta uma reduzida capacidade de escoamento devido ao agravamento de processos antropológicos como impermeabilização do solo e entulhamento do corpo hídrico por sedimentos e lixo doméstico. Porém, como sugere Candido Bay e Silva (2011), embora exista uma percepção da população sobre os problemas ambientais, geralmente os moradores aceitam conviver com essas adversidades, assumindo uma atitude passiva, pois muitas vezes não conseguem entender a importância da Saúde Ambiental (conceito que engloba os problemas resultantes dos efeitos que o ambiente exerce sobre o bem-estar físico e mental do ser humano). De posse do conhecimento desse conceito, é necessário que os moradores cobrem ações do poder público no sentido de melhorar os cuidados com o ambiente (RODRIGUES et al., 2012), mas que também exerçam seu papel de cidadão com o meio ambiente, buscando sempre agir com respeito, solidariedade e responsabilidade, para assim contribuir para a construção de um mundo ecologicamente equilibrado (LAYRARGUES, 1997). 
Figura 3: Gráfico: Opinião dos alunos sobre a Saúde Ambiental do rio Sarapuí.

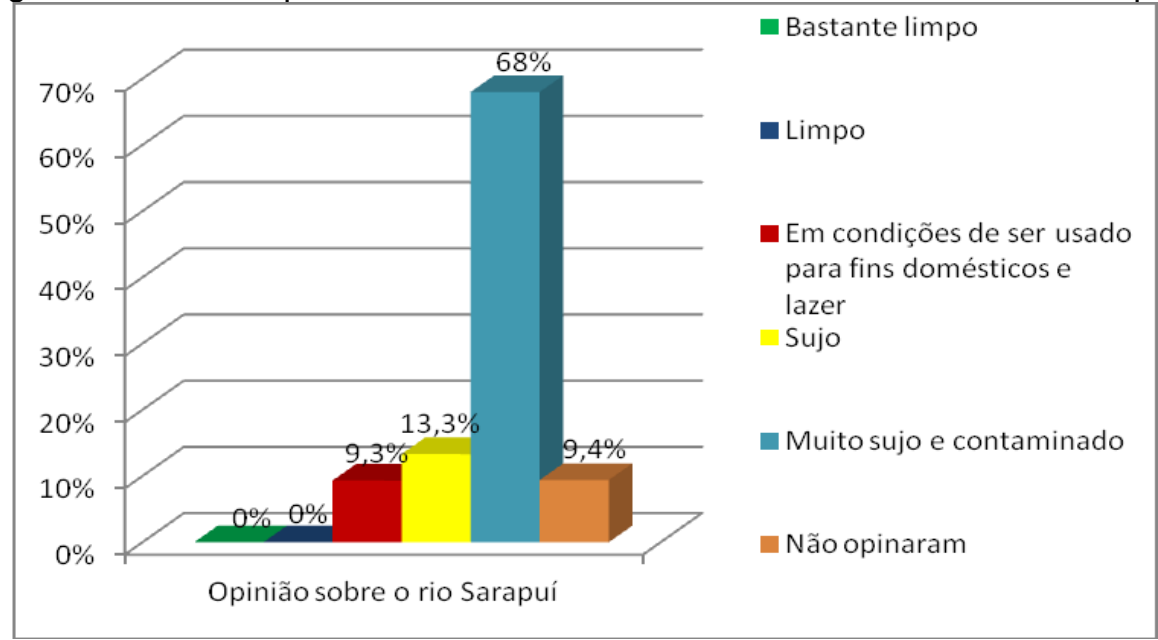

Fonte: Elaboração dos próprios autores.

Verifica-se ainda que o número de alunos que não opinaram sobre o fato de o rio Sarapuí possuir seres vivos foi bastante expressivo (Figura 4). Pires (2006) e Santana (2011) registram, em pesquisa realizada, que a biodiversidade outrora observada no rio Sarapuí, encontra-se hoje bastante reduzida. E se de fato existem seres vivos nesse curso d'água, provavelmente os mesmos encontram-se bastante prejudicados devido a contaminação desse rio pelos metais: Arsênio (As), Cromo $(\mathrm{Cr})$, Cobre $(\mathrm{Cu})$, Chumbo $(\mathrm{Pb})$, Vanádio $(\mathrm{V})$, Zinco $(\mathrm{Zn})$, Cádmio $(\mathrm{Cd})$ e Mercúrio (Hg) (ALMEIDA et al., 2013; SILVEIRA et al., 2011; BARROCAS; WASSERMAN, 1995). O biólogo Mário Moscatelli registra que análises de água em alguns trechos mostram que os níveis de oxigênio dissolvido na água do rio Sarapuí chegam a $0,7 \mathrm{mg} / \mathrm{L}$ de amostra coletada, sendo que para haver vida aquática garantida o mínimo necessário é de 5mg/L (JUNQUEIRA, 2010a). 


\section{Atos de Pesquisa em Educação - ISSN 1809-0354 \\ Blumenau, v.14, n.2, p.478-500, mai./ago. 2019 \\ DOI: http://dx.doi.org/10.7867/1809-0354.2019v14n2p478-500}

Figura 4: Gráfico: Percepção dos alunos a respeito da presença de seres vivos no rio Sarapuí.

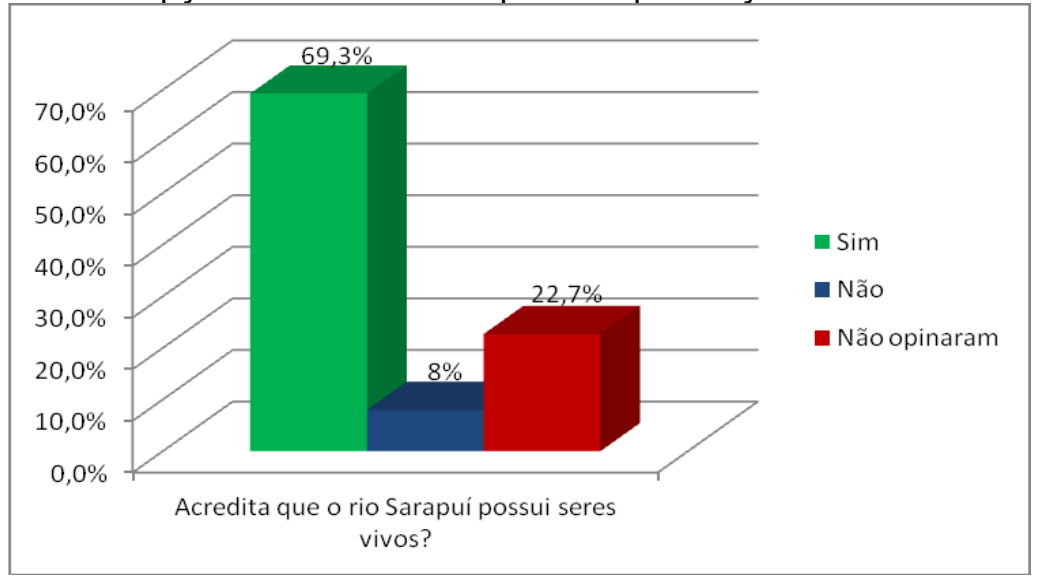

Fonte: Elaboração dos próprios autores.

Apenas $45,3 \%$ dos discentes acham que o rio é importante (Figura 5), o que evidencia e evoca a necessidade de se desenvolver trabalhos de EA com esses alunos. Santana $(2011$, p.1) relata que "O entorno do rio Sarapuí é cercado por comunidades carentes e que ainda sobrevivem dele, recolhendo materiais recicláveis que são despejados diariamente nesse rio".

Figura 5: Gráfico: Percepção dos alunos acerca da importância do rio Sarapuí.

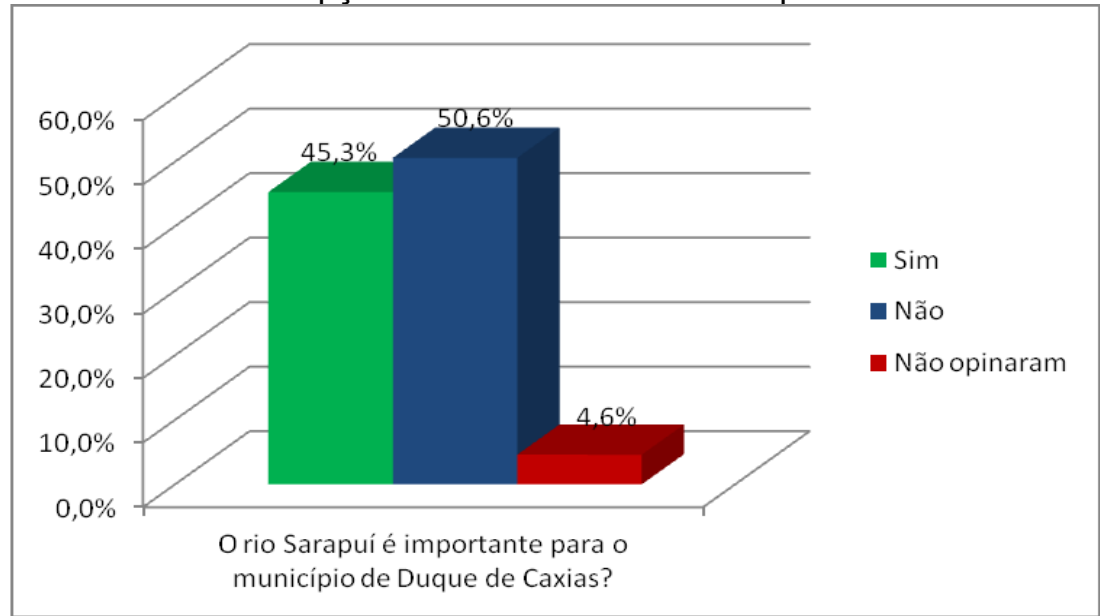

Fonte: Elaboração dos próprios autores.

A fala de Claudio Matias dos Santos (relato retirado de excertos do trabalho de Junqueira, 2010b), pescador de 33 anos, registra a importância que esse rio um dia já possuiu:

Ainda cheguei a pegar peixe nesse rio. Mas faz tempo que isso acabou. Cada vez temos que ir mais longe da foz para conseguir pescar. Quando chove, desce muito lixo, não consigo pescar nem uns 20 quilos de peixe. Num dia bom de pesca, em local limpo, é possível trazer de 80 a 100 quilos de pescado para casa (JUNQUEIRA, 2010b, p.1). 
O pescador contou que descia, em barco a motor, por cerca de 40 minutos o rio, até chegar a uma parte bem distante da Baía de Guanabara para conseguir levar para casa seu sustento: "A remo, gasto mais de uma hora nesse trajeto. Na foz, a água é totalmente negra e o cheiro, insuportável. Há pontos por ali que já são só lama” (JUNQUEIRA, 2010b, p.1).

Relatos encontrados em trabalhos como o de Junqueira (2010b) coadunam com os PCNs (BRASIL, 1998) sobre a importância da aproximação de conhecimentos populares e escolares no que tange à sensibilização e conscientização ambiental dos estudantes, professores, funcionários, enfim, de todos os sujeitos que atuam e se envolvem com a escola e com a comunidade onde se encontram inseridos. A escola necessita conhecer os problemas da comunidade local, inclusive no parâmetro ambiental, assim como a comunidade precisa participar da vida escolar.

Nesse sentido, a Figura 6 demonstra o perfil dos alunos participantes, sendo em sua maioria, moradores da comunidade local.

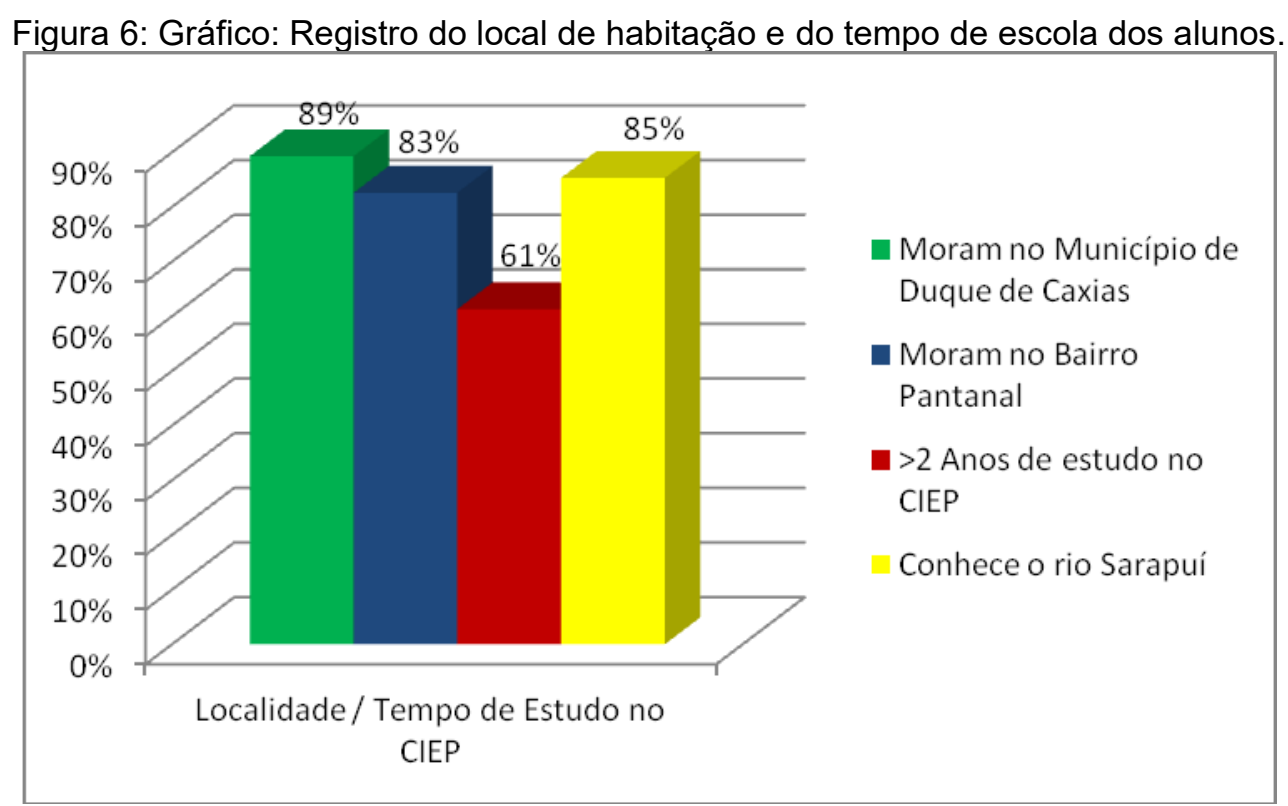

Fonte: Elaboração dos próprios autores.

Quando perguntados "sobre as formas com que se relacionam com o rio Sarapuí", $88 \%$ dos alunos responderam que apenas veem o rio; $5,3 \%$ que o utilizam para lavar louça e 5,3\% para lazer (Figura 7). A maior parte dos alunos considera o 
rio apenas como um elemento da paisagem, ou seja, é apenas visto e não observado. Quando se diz que algo é observado, pode-se inferir que há um tempo dedicado para análise, para contemplação, para prestar atenção. Já quando se diz que algo é visto, pode-se inferir que é apenas olhar para algo, ver por passar por ele, ou seja, não se atentar para contemplação. Provavelmente essa população não possui consciência dos problemas que a contaminação desse curso d'água pode causar, como por exemplo, a transmissão de doenças (ANTUNES et al., 2014). Sendo assim, é necessário educar esse público, mostrando que a contaminação das águas pode trazer o risco de transmissão de várias doenças infectocontagiosas, como febre tifóide, hepatites e giardíase (OPS, 2007). Educando essa população, será possível que os alunos passem a observar e não apenas ver os problemas existente ao seu entorno.

Para a Educação Ambiental Crítica, é necessário que tanto a população quanto a escola, sejam conclamados à ação, ou seja, os sujeitos que, à priori, estavam excluídos de participação e de voz sobre os aspectos ambientais que os rodeiam, agora tornam-se sujeitos ativos.

Figura 7: Gráfico: Formas de relacionamento dos alunos com o rio Sarapuí.

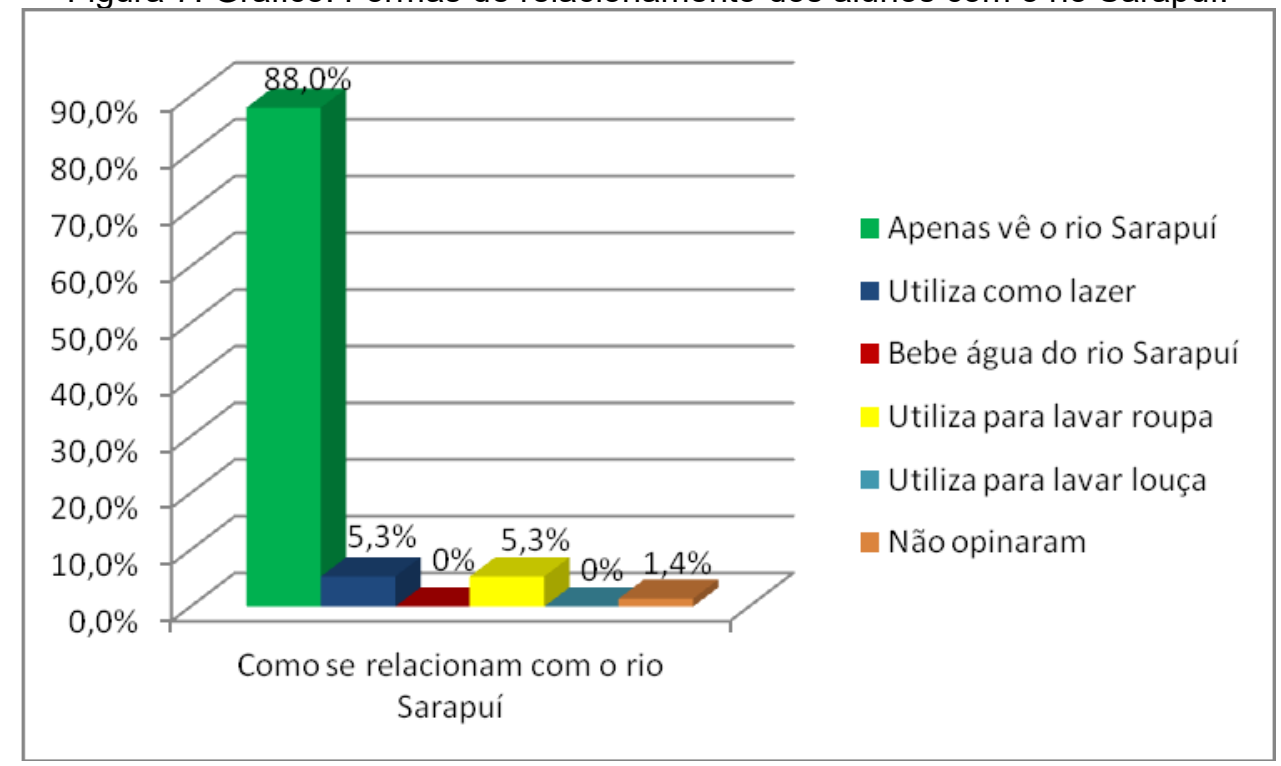

Fonte: Elaboração dos próprios autores.

Sobre a percepção dos alunos quanto a relação que se pode estabelecer entre o rio Sarapuí e o Ensino de Ciências, 81,3\% dos alunos acreditam que alguns conteúdos sobre o rio Sarapuí poderiam ser ensinados nas aulas de Ciências 
(Figura 8). E de fato, muitos conceitos científicos podem ser trabalhados nas aulas, como por exemplo, metais pesados, saúde, biodiversidade, políticas ambientais, dentre outros.

O interessante seria questionar os alunos sobre quais efeitos, por exemplo, a contaminação desse curso hídrico por metais pesados poderia ocasionar para a comunidade de peixes e para a população humana de Duque de Caxias.

Figura 8: Gráfico: Percepção dos alunos sobre a relação que se pode estabelecer entre o rio Sarapuí e o Ensino de Ciências.

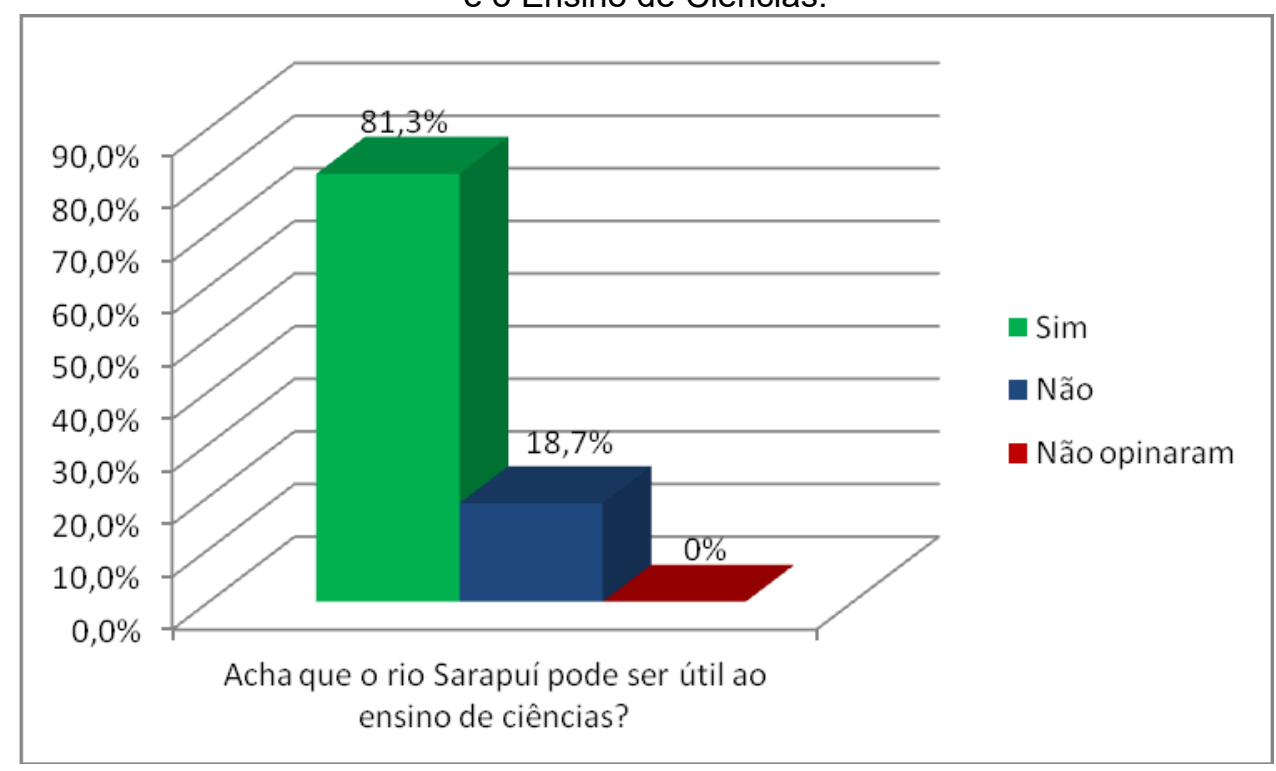

Fonte: Elaboração dos próprios autores.

Quase todos os alunos pesquisados, mais especificamente $96 \%$, declararam nunca ter feito atividades escolares associadas ao rio (Figura 9). Portanto, fica evidente a necessidade de se explorar nas aulas de Ciências e de outras disciplinas escolares, a importância desse rio para a comunidade de Duque de Caxias. Afinal, o próprio Currículo Mínimo, designado pela Secretaria de Estado de Educação (RIO DE JANEIRO, 2017), determina que, no $7^{\circ}$ Ano do Ensino Fundamental, é essencial que os alunos:

- Compreendam a relação existente entre doenças vinculadas à água, como a cólera, a leptospirose, a esquistossomose, a dengue e o cuidado individual, coletivo e governamental com o ambiente;

- Identifiquem os componentes naturais e sociais dos ecossistemas;

- Reconheçam fatores de risco para o desequilíbrio na teia alimentar;

- Elaborem propostas para preservação das espécies e ambientes ameaçados. 


\section{Atos de Pesquisa em Educação - ISSN 1809-0354 \\ Blumenau, v.14, n.2, p.478-500, mai./ago. 2019 \\ DOI: http://dx.doi.org/10.7867/1809-0354.2019v14n2p478-500}

Nesse sentido, como sugerem Bizerril e Faria (2001), disciplinas que podem ser úteis para trabalhar as questões ambientais são Ciências, Geografia e História.

Figura 9: Gráfico: Registra se os alunos já fizeram alguma atividade escolar a respeito do rio Sarapuí.

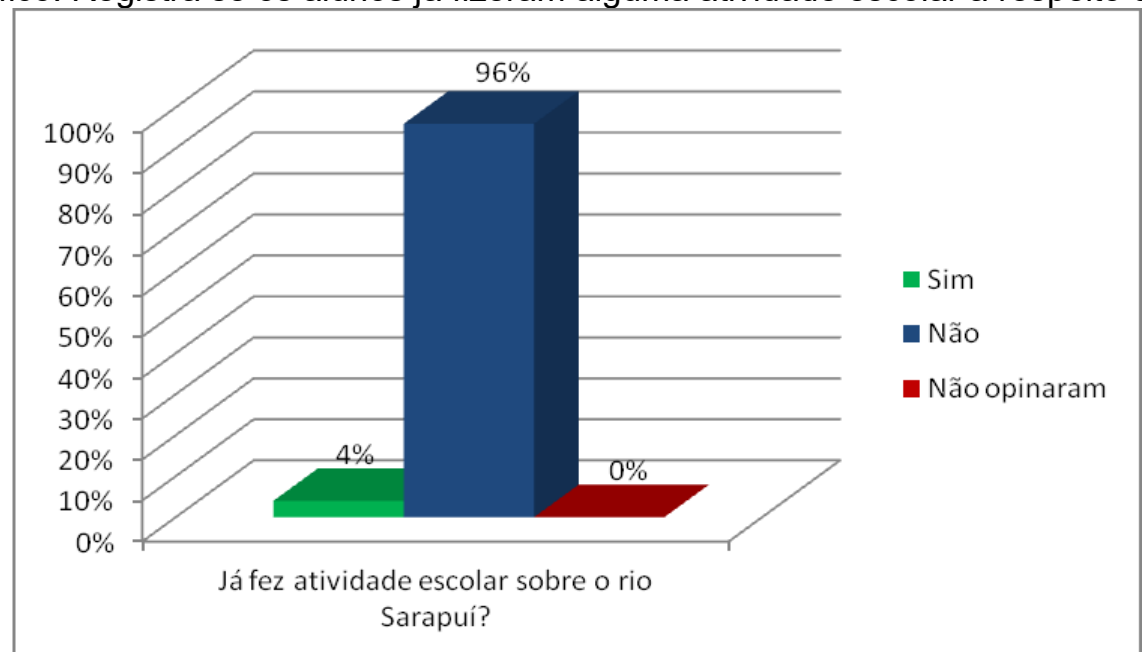

Fonte: Elaboração dos próprios autores.

Quanto a percepção dos benefícios do rio aos moradores, 62,6\% dos alunos mostraram não perceber nenhum benefício do rio para os moradores daquela região, enquanto $30,6 \%$ dos alunos perceberam esses benefícios (Figura 10). E realmente, na atualidade, o rio Sarapuí não gera tantos benefícios como antes. Atualmente, encontra-se em estado de assoreamento, está extremamente poluído, é destino de dejetos industriais e domésticos da população que vive às suas margens e a biodiversidade que antes o compunha está ausente (SANTANA, 2011). Porém, até a metade do século passado, era um rio navegável e que servia como fonte de sobrevivência para os pescadores da região (SANTANA, 2011). 
Figura 10: Gráfico: Percepção dos alunos acerca de possíveis benefícios do rio Sarapuí aos moradores.

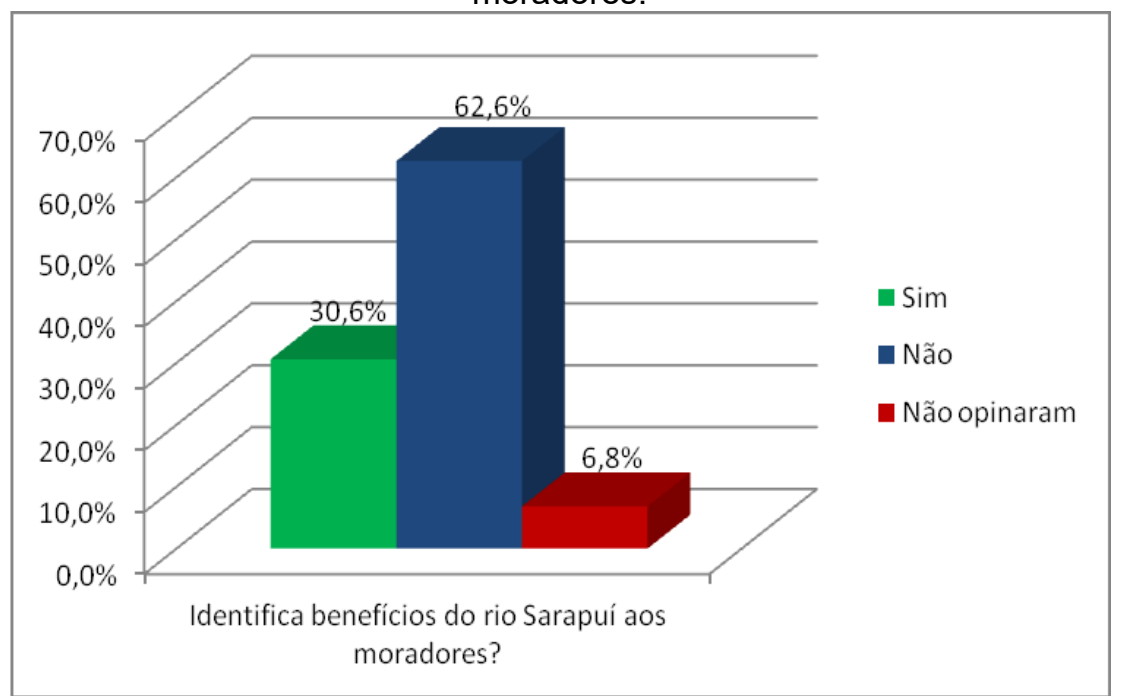

Fonte: Elaboração dos próprios autores.

\section{CONSIDERAÇÕES FINAIS}

A presente pesquisa evidenciou a necessidade de se esclarecer melhor a importância que o rio Sarapuí possui, aos alunos do $7^{\circ}$ Ano do Ensino Fundamental, já que apenas $45,3 \%$ dos discentes entendem a importância do rio. $E$ da mesma forma, alertar aos alunos sobre os perigos existentes ao manter-se um contato com as águas desse curso hídrico, que se encontra completamente contaminado, pois $5,3 \%$ dos alunos utilizam o rio para lavar louça e 5,3\% para lazer. Interessante também seria instruir os estudantes sobre o local em que se localiza a nascente desse rio, uma vez que $93,3 \%$ dos discentes não sabem a sua localização.

Diante dos resultados encontrados é de suma importância que todo indivíduo, enquanto sujeito da história, seja ativo diante de seus deveres e suas responsabilidades para com o meio em que vive, participando diretamente de ações que vão além da sustentabilidade (GUIMARÃES, 2007).

Portanto, o conhecimento da percepção ambiental que essa população de Duque de Caxias possui sobre o rio Sarapuí permite ao gestor planejar e elaborar projetos em Educação Ambiental; além de avaliar, estimular e propor ações mitigadoras dos impactos ambientais existentes na área. Assim, espera-se que esta 
Atos de Pesquisa em Educação - ISSN 1809-0354

Blumenau, v.14, n.2, p.478-500, mai./ago. 2019

DOI: http://dx.doi.org/10.7867/1809-0354.2019v14n2p478-500

pesquisa subsidie a elaboração de campanhas educativas e projetos de intervenção ambiental, capazes de envolver a sociedade como um todo.

Sugerimos, para investigações futuras, que sejam desenvolvidas pesquisas em Educação Ambiental ao longo das 21 favelas que estão presentes ao longo do percurso do rio Sarapuí. Entendemos que tais pesquisas podem colaborar para um maior conhecimento por parte dos alunos acerca da necessidade do saneamento básico, do cuidado com o lixo e com os esgotos domésticos.

\section{JULIANA MACEDO LACERDA NASCIMENTO}

Doutora em Ciências pelo Programa de Pós-Graduação em Ensino em Biociências e Saúde - Fundação Oswaldo Cruz (FIOCRUZ- RJ). Professora da Pós-Graduação em Ensino de Ciências e Biologia da Universidade do Estado do Rio de Janeiro (UERJ); Professora da Secretaria de Estado de Educação e da Secretaria Municipal de Educação do Rio de Janeiro.

\section{LUCAS DE ESQUIVEL DIAS BRANDÃO}

Bacharel e Licenciado em Ciências Biológicas pela Pontifícia Universidade Católica de Minas Gerais (PUC Minas).

\section{MARCELO DINIZ MONTEIRO DE BARROS}

Doutor em Ensino em Biociências e Saúde pelo Instituto Oswaldo Cruz (FIOCRUZ). Professor Permanente do Programa de Pós-Graduação em Ensino em Biociências e Saúde (PG-EBS) do Instituto Oswaldo Cruz. Professor Adjunto IV do Departamento de Ciências Biológicas da Pontifícia Universidade Católica de Minas Gerais (PUCMG). Professor nível IV, Grau A, da Faculdade de Educação da Universidade do Estado de Minas Gerais (UEMG). Professor do Programa de Pós-Graduação em Educação: Educação e Formação Humana da UEMG.

\section{REFERÊNCIAS}

ALMEIDA, B. J.; et al. Análise de parâmetros físicos e químicos da água do rio Sarapuí, no município de Duque de Caxias (RJ). In: 53० CONGRESSO BRASILEIRO DE QUÍMICA, 2013, Rio de Janeiro.

ANTUNES, C. M. M.; et al. Qualidade das águas e percepção de moradores sobre um rio urbano. Revista Brasileira de Ciências Ambientais, Rio de Janeiro. n. 32, p. 75-87, jun. 2014.

ARAÚJO, F. P; COREIXAS, M. A. Nossos Rios. In: NEGREIROS, D. H. (Org.). Nossos Rios. Niterói: Instituto Baía de Guanabara, 2002. 31p. 
Atos de Pesquisa em Educação - ISSN 1809-0354

Blumenau, v.14, n.2, p.478-500, mai./ago. 2019

DOI: http://dx.doi.org/10.7867/1809-0354.2019v14n2p478-500

BACCEGA, M. A. Novas tecnologias, novas sensibilidades. Revista Comunicação \& Educação, São Paulo: Segmento, n. 18, p. 7-14, maio/ago. 2000. Disponível em: <http://dx.doi.org/10.11606/issn.2316-9125.v0i18p7-14>. Acesso em: 12/06/2014.

BARBOSA, D. R.; et al. Riscos Ambientais na Cabeceira da Bacia do Rio Sarapuí (Zona Oeste do Rio de Janeiro). In: $9^{\circ}$ SINAGEO - Simpósio Nacional de Geomorfologia, 2012, Rio de Janeiro.

BARROCAS, P. R. G.; WASSERMAN, J. C. F A. O mercúrio na baía de Guanabara: Uma revisão histórica. Geochimica Brasiliensis. Pernambuco, v. 9, n. 2, p.115-127, jul/dez. 1995.

BARROS, A. J. S.; LEHFELD, N. A. S. Fundamentos de metodologia científica. 3. ed. São Paulo: Pearson/Prentice Hall, 2007, 158 p.

BEZERRA, T. M. O.; FELICIANO; A. L. P.; ALVES, A. G. C. Percepção ambiental de alunos e professores do entorno da Estação Ecológica de Caetés - Região Metropolitana do Recife (PE). Biotemas, Florianópolis, v. 21, n.1, p. 147-160, março. 2008.

BIZERRIL, M. X. A.; FARIA, D. S. Percepção de professores sobre a educação ambiental no ensino fundamental. Revista Brasileira de Estudos Pedagógicos (Impresso), Brasília, v. 82, n.200/201/202, p. 57-69, jan/dez. 2001.

BOMFIM, A. M. Trabalho, Meio Ambiente e Educação: apontamentos à Educação Ambiental a partir da Filosofia da Práxis. In: XIV ENDIPE, 2008, Porto Alegre, EDIPUC-RS, 2008. p.1-14.

BRASIL. Resolução CONAMA 357, de 17 de março de 2005. Dispõe sobre a classificação de corpos de água e diretrizes ambientais para o seu enquadramento, bem como estabelece as condições e padrões de lançamento de efluentes, e dá outras providências. Diário Oficial da União, Brasília, DF, n. 53, 18 de março de 2005.

BRASIL. Parâmetros Curriculares Nacionais: terceiro e quarto ciclos do ensino fundamental: introdução aos parâmetros curriculares nacionais. Secretaria de Educação Fundamental. Brasília: MEC/SEF, 1998.

CAMPOS, F. B. L. Gestão de bacias hidrográficas urbanas - estudo de caso da bacia hidrográfica do rio Iguaçu-Sarapuí - Rio de Janeiro. 2004.157p. Dissertação (Mestrado) - Programa de Pós-graduação em Engenharia Ambiental. Universidade do Estado do Rio de Janeiro, Rio de Janeiro.

CANDIDO BAY, A. M.; SILVA, V. P. Percepção ambiental de moradores do bairro de liberdade de Parnamirim (RN) sobre a implantação do esgotamento sanitário. Holos, Rio Grande do Norte, v. 27, n.3, p. 97-112, maio. 2011. 
Atos de Pesquisa em Educação - ISSN 1809-0354

Blumenau, v.14, n.2, p.478-500, mai./ago. 2019

DOI: http://dx.doi.org/10.7867/1809-0354.2019v14n2p478-500

CARNEIRO, P. R. F.; MIGUEZ, M. G. A Flood Control Approach Integrated with a Sustainable Land Use Planning in Metropolitan Regions. In: Environmental Land Use Planning. 1ed. Croatia: InTech, v. 1, p. 135-158, nov. 2012.

CARNEIRO, P. R. F.; et al. A Gestão Integrada de Recursos Hídricos e do Uso do Solo em bacias urbano-metropolitanas: o controle de inundações na bacia dos rios Iguaçu/Sarapuí, na Baixada Fluminense. Ambiente e Sociedade, Campinas, v. 13, n.1, p. 29-49, jan/jun. 2010.

BRASIL. Ministério da Saúde. CONSELHO NACIONAL DE SAÚDE. Resolução No 510, de 07 de abril de 2016. Diário Oficial (da) República Federativa do Brasil, Brasília, DF, n. 98, p. 44-46, 24 maio 2016. Seção 1.

CREA-RJ. Conselho Regional de Engenharia e Agronomia do Rio de Janeiro. Inspeções realizadas pelo CREA-RJ em áreas de baixada que sofreram enchentes decorrentes das fortes chuvas em dezembro/2013. Relatório, Rio de Janeiro, dez. 2013.

CORDEIRO, L. G. M. S. Esteróis como marcadores moleculares da contaminação fecal no sistema estuarino Iguaçu-Sarapuí, noroeste da Baía de Guanabara (RJ). 2006. 170p. Dissertação (Mestrado) - Programa de Pós-graduação em Química. Pontifícia Universidade Católica do Rio de Janeiro, Rio de Janeiro.

COSTA, R. N.; FARIAS, M. F. Monitoramento do Rio Macaé com base na participação das Escolas Públicas, uma ação para a sustentabilidade. Revista Visões, Bela Vista Macaé, 4. ed, v.1, n. 4. jan/jun. 2008.

DEL RIO, V.; OLIVEIRA, L. Percepção ambiental: a experiência brasileira. 2. ed. São Paulo: Studio Nobel, 1999, 265p.

FERNANDES, R. S.; et al. Uso da Percepção Ambiental como Instrumento de Gestão em Aplicações Ligadas às Áreas Educacional, Social e Ambiental. Revista Científica UNIVIX, Vitória, v. 2, p. 33-45, s/d. 2004.

FRANCO, A. R.; et al. Estudo de percepção ambiental com alunos de escola municipal localizada no entorno do Parque Estadual da Serra do Rola-Moça. Ambiente \& Educação, Rio Grande, v. 17, n. 1, p. 155-175, jan/jun. 2012.

GUIMARÃES, M. Educação ambiental: no consenso um debate? Campinas: Papirus, 2000, 94p.

$174 p$.

. A formação de educadores ambientais. Campinas: Papirus. 2007,

JUNQUEIRA, F. Aterro de Gramacho e lixo no rio Sarapuí pioram contaminação. 03 jun. 2010. 2010a. Disponível em: <https://extra.globo.com/noticias/rio/aterro-degramacho-lixo-no-rio-sarapui-pioram-contaminacao-372098.html>. Acesso em: 20 abr. 2018. 
Atos de Pesquisa em Educação - ISSN 1809-0354

Blumenau, v.14, n.2, p.478-500, mai./ago. 2019

DOI: http://dx.doi.org/10.7867/1809-0354.2019v14n2p478-500

. Peixes sumiram do Rio Sarapuí, acabando com o sustento de

pescadores. 02 jun.2010. 2010b. Disponível em:

$<$ http://extra.globo.com/noticias/rio/peixes-sumiram-do-rio-sarapui-acabando-com-

sustento-de-pescadores-372005.htm|\#ixzz3dLOP4fth>. Acesso em: 17 jun. 2015.

KRASILCHIK, M.; CARVALHO, L. M.; SILVA, R. L. F. Educação para a sustentabilidade dos recursos hídricos. In: BICUDO, C. E. M.; TUNDISI, J. G., SCHEUENSTUHL, M. C. B. (orgs.). Águas do Brasil - Análises Estratégicas. São Paulo: Instituto de Botânica, v. 1, 2010, p. 133-144.

LAYRARGUES, P. P. Do ecodesenvolvimento ao desenvolvimento sustentável: evolução de um conceito? Revista Proposta, Rio de Janeiro, v. 24, n. 71, p. 1-5, s/d. 1997.

LISBOA, C. P.; KINDEL, E. A. I.; KROB, A. J. D. Educação Ambiental: da Teoria à Prática. Porto Alegre: Mediação, 2012, 144p.

LOUREIRO, C. F. B. Trajetória e fundamentos da educação ambiental. São Paulo: Cortez, 2004.150p.

MALAFAIA, G.; RODRIGUES, A. S. L. Percepção ambiental de jovens e adultos de uma escola municipal de ensino fundamental. Revista Brasileira de Biociências, Porto Alegre, v. 7, n. 3, p. 266-274, jul./set. 2009.

MARIN, A. A. Percepção ambiental e imaginário dos moradores do município de Jardins (MS). 2003. 306 p. Tese (doutorado). - Centro de Ciências Biológicas e da Saúde. Universidade Federal de São Carlos, São Carlos.

MELAZO, G. C. Percepção ambiental e educação ambiental: uma reflexão sobre as relações interpessoais e ambientais no espaço urbano. Olhares \& Trilhas, Uberlândia, v. 6, n. 1, p. 45-51, jan./dez. 2005.

MELLO, S. S; TRAJBER, R. Vamos cuidar do Brasil: conceitos e práticas em educação ambiental na escola. Brasília: Ministério da Educação, Coordenação Geral de Educação Ambiental: Ministério do Meio Ambiente, Departamento de Educação Ambiental: UNESCO, 2007.

MOURA, P. N.; PEREIRA, T. V. C. Análises da contribuição de esgotos sanitários ao rio Sarapuí de acordo com o prognóstico das bacias de esgotamento da região: aplicação dos modelos de Streeter-Phelps. 2016. 101p. Monografia (Engenharia Ambiental) - Escola Politécnica. Universidade Federal do Rio de Janeiro, Rio de Janeiro.

OLIVEIRA, K. A.; CORONA, H. M. P. A percepção ambiental como ferramenta de propostas educativas e de políticas ambientais. ANAP Brasil Revista Cientifica, v.1, n. 1, jul. 2008. 
OPS. Organización Panamericana de la Salud. Salud en las Américas. 2007. Washington: OPS, v. I, cap. 3, p. 220-313, 2007.

PENSAMENTO VERDE. A importância da preservação dos rios e nascentes. 2014. Disponível em: < http://www.pensamentoverde.com.br/meio-ambiente/importanciada-preservacao-dos-rios-e-nascentes/>. Acesso em: 17 jun. 2015.

PIRES, L. E. B. Avaliação e identificação da toxidade do efluente líquido do pólo industrial de Belford Roxo, RJ, e sua contribuição na qualidade das águas do corso inferior do rio Sarapuí, Sub-bacia do rio Iguaçu, Bacia da Baía de Guanabara, RJ, Brasil. 2006. 175p. Tese (Doutorado) - Programa de Pós-Graduação em Ciências na área de Tecnologia Nuclear, Universidade de São Paulo, São Paulo.

RIO DE JANEIRO (Estado). Secretaria de Estado de Educação do Rio de Janeiro, SEEDUC. Currículo Mínimo, 2017.

RODRIGUES, M. L; et al. A percepção ambiental como instrumento de apoio na gestão e na formulação de políticas públicas ambientais. Saúde e Sociedade, São Paulo, v. 21, supl. 3, p. 96-110, dez./2012. Disponível em:

<http://dx.doi.org/10.1590/S0104-12902012000700009>. Acesso em: 12/06/2014.

SANTANA, T. O Rio Sarapuí e as Implicações Cotidianas Vivenciadas pelos Moradores do Município de Duque de Caxias - RJ. nov., 2011. Disponível em: < http://www.trabalhosfeitos.com/ensaios/o-Rio-Sarapu\%C3\%AD-e-AsImplica\%C3\%A7\%C3\%B5es/893473.html>. Acesso em: 17 jun 2015.

SILVEIRA, R. P.; et al. Mass balance in the monitoring of pollutants in tidal Rivers of the Guanabara Bay, Rio de Janeiro, Brazil. Environmental Monitoring and Assessment, Holanda, v.181, n. 1-4. p.165-173. out. 2011. Disponível em: <doi: 10.1007/s10661-010-1821-9>. Acesso em: 12/06/2014.

TURATO, E. R. Métodos qualitativos e quantitativos na área da saúde: definições, diferenças e seus objetivos de pesquisa. Revista de Saúde Pública, São Paulo, v. 39, n. 3, p. 507-514, jun. 2005.

\section{Apêndice I}

\section{Pesquisa em Ensino em Biociências e Saúde}

\section{Questionário}

Percepção ambiental dos alunos de uma escola pública Estadual acerca do rio Sarapuí (Duque de Caxias)

1) Idade :

2) Sexo:M( ) F( ) 
Atos de Pesquisa em Educação - ISSN 1809-0354

Blumenau, v.14, n.2, p.478-500, mai./ago. 2019

DOI: http://dx.doi.org/10.7867/1809-0354.2019v14n2p478-500

3) Mora em qual município?

4) Em qual bairro?

5) Há quantos anos estuda nesta escola?

6) Conhece o rio Sarapuí? Sim ( ) Não ( )

7) Caso conheça o rio Sarapuí como se relaciona com ele?

( ) Apenas vejo o rio;

( ) Utilizo como lazer;

( ) bebo a água do rio;

( ) Utilizo a água para lavar roupas sujas;

( ) Utilizo a água para lavar vasilhas.

8) Você entende que o rio Sarapuí é importante para o município de Duque de Caxias? Sim ( ) Não ( ). Em caso afirmativo, por quais motivos acha o rio importante?

9) Acredita que o rio Sarapuí possa conter seres vivos? Sim ( ) Não ( ). Em caso afirmativo quais?

10) Você sabe em qual local fica a nascente do rio Sarapuí? Sim ( ) Não ( ). Em caso afirmativo, onde?

11) Conhece algum malefício que o rio Sarapuí trouxe aos moradores do bairro que o atravessa? Sim ( ) Não ( ). Em caso afirmativo, Qual (is)?

12) Conhece algum benefício que o rio Sarapuí trouxe aos moradores do bairro que o atravessa? Sim ( ) Não ( ). Em caso afirmativo, Qual (is)?

13) Em sua opinião, o rio Sarapuí é:

( ) Bastante limpo

( ) Limpo

( ) Nem sujo nem limpo, em condições para ser utilizado para fins domésticos e lazer

( ) Sujo, sem condições de uso doméstico e lazer 
Atos de Pesquisa em Educação - ISSN 1809-0354

Blumenau, v.14, n.2, p.478-500, mai./ago. 2019

DOI: http://dx.doi.org/10.7867/1809-0354.2019v14n2p478-500

( ) Muito sujo e contaminado

14) Você já fez alguma atividade escolar sobre o rio Sarapuí? Sim ( ) Não ( ). Em caso afirmativo qual (is)?

15) Você acha que o rio Sarapuí poderia ser útil ao Ensino de Ciências em sua escola? Sim ( ) Não ( ). Em caso afirmativo, sugira o que gostaria de aprender em Ciências através do rio Sarapuí: 